\title{
Kinetic Study of an H-ZSM-5/Al-MCM-41 Catalyst Mixture and Its Application in Lignocellulose Biomass Pyrolysis
}

\author{
Devy K. Ratnasari,*(i) Weihong Yang, and Pär G. Jönsson \\ Department of Material Science and Engineering, KTH-Royal Institute of Technology, Brinellvägen 23, Stockholm 100 44, Sweden
}

\begin{abstract}
The use of H-ZSM-5 and Al-MCM-41 in a two-stage system of mesoporous and microporous catalysts has been proved to improve the quality of bio-oil. Information about biomass pyrolysis kinetics is important to evaluate biomass as a feedstock for fuel or chemical production as well as efficient design and control of thermochemical processes. In this study, the catalytic pyrolysis kinetics of lignocellulose biomass with a mixed catalyst of H-ZSM-5 and Al-MCM-41 at different ratios is analyzed. The derived activation energies are determined using the Coats-Redfern model and an Avrami mechanism for firstorder chemical reactions (A1, F1). Bench-scale experiments as well as quantifications of the resulted benzene, toluene, and xylene (BTX) yields have also been investigated. The thermogravimetric analysis-DTG results show that the presence of catalyst mixtures has significant effects on the fractions of volatile matter from lignocellulose biomass. Reactivity profiles have been obtained in the temperature range of 180 to $360^{\circ} \mathrm{C}$. The results show that the energy activation for lignocellulose biomass at a heating rate of $10 \mathrm{~K} \mathrm{~min}^{-1}$ is $134.64 \mathrm{~kJ} \mathrm{~mol}^{-1}$ and that the value decreases when using catalysts. However, when the heating rate is increased, the activation energy from the catalytic experiments is $6.3-66.0 \%$ higher than that from the biomass pyrolysis experiment. This is due to the production of coke. Overall, a H-ZSM-5/Al-MCM-41 ratio of 3:1 is found to be the best catalyst ratio in cracking hemicellulose and cellulose compared to other catalyst mixtures that were studied. The same catalyst ratio also attains the best interaction, in terms of a BTX product selectivity. The optimum activity of this catalyst mixture is reached at a temperature of $500{ }^{\circ} \mathrm{C}$.
\end{abstract}

\section{INTRODUCTION}

In the coming decades, the demand for energy is expected to rise globally. According to the International Energy Agency, a 55 percent increase of the energy needs is predicted during 2005 and 2030 because of the growing population and economic developments. ${ }^{1}$ Currently, the primary energy supply for global energy needs is based on fossil fuels. The energy from domestic heating and electricity to fuel for transportation relies mostly on oil, coal, and natural gas. Oilbased products in the form of petrol, diesel, and aviation fuel are mainly used in the transportation sector. Thus, the growth in oil demand is mainly due to the growth in the transportation sector. However, fossil fuels are nonrenewable. The continuous consumption will conclude in its final depletion. ${ }^{2}$ Thus, a great deal of development and production of energy from alternative sources other than fossil fuels is needed.

Biomass is considered to be one of the most potential renewable energy sources to replace fossil fuels, as it can be converted into liquid, solid, and gaseous fuels. ${ }^{3,4}$ Additionally, the rational use of biomass does not contribute to a net rise in the level of $\mathrm{CO}_{2}$ in the atmosphere. ${ }^{5}$ One of the promising biomass materials for fossil fuel replacement is lignocellulose biomass. The availability of lignocellulose biomass is abundant. It is also known to be the cheapest and fastest growing of the biomass materials. ${ }^{6}$ However, because of its complex structure, it is difficult to produce a high quantity and quality of bio-oil from lignocellulose.

The production of liquid biofuels and chemicals from biomass is vastly conducted by thermochemical conversion processes. The thermochemical process in the absence of oxygen is known as pyrolysis. During this pyrolysis process, the molecules of biomass are broken down to liquid products and noncondensable gases as well as to carbon-rich char. Fuels and various chemicals can be derived from the liquid products because of their high caloric values. ${ }^{7}$ In the pyrolysis process, this liquid product is produced in a higher yield compared to gas and solid products. The liquid product is less toxic, has a better lubricity, as well as a stronger biodegradation. ${ }^{8}$ However, the raw pyrolysis oil has several drawbacks, such that it is highly oxygenated, ${ }^{9}$ acidic $^{10}$ and corrosive, ${ }^{9,10}$ unstable ${ }^{9,11}$ and chemically complex, ${ }^{9}$ contains inert mineral ash and unreformed carbon, ${ }^{12}$ which limit its applications. Therefore, it is necessary to upgrade the raw pyrolysis oil by selecting a proper upgrading technique.

Considering several factors, such as costing, efficiency, and easy handling of the system, the catalytic pyrolysis method is found to be one of the most promising methods because of a low-cost and a straightforward system. ${ }^{8,13}$ However, a suitable catalyst needs to be employed to achieve the desired products. $^{14}$

Vitolo et al. ${ }^{15}$ studied catalytic pyrolysis using H-ZSM-5 and found that deoxygenation, decarboxylation, and decarbonylation as well as cracking, alkylation, isomerization, cyclization, oligomerization, and aromatization were initiated by employing an H-ZSM-5 catalyst in the thermochemical process. ${ }^{15}$ The H-ZSM-5 catalyst was proved to have the best performance in producing aromatic hydrocarbon, ${ }^{16}$ which implies that H-ZSM-5 improves the quality of bio-oil produced from pyrolysis of lignocellulose biomass. However, the

Received: March 20, 2019

Revised: April 16, 2019

Published: May 1, 2019 
Table 1. Properties of Lignocellulose Biomass ${ }^{a}$

\begin{tabular}{lcl} 
& \multicolumn{2}{c}{ proximate analysis (wt \%) } \\
\hline volatiles, db & 84.2 & SS-EN ISO 18123:2015 \\
moisture, $105{ }^{\circ} \mathrm{C}$ & 14.1 & SS-EN ISO 18134-1:2015/-2:2017 \\
ash, $550{ }^{\circ} \mathrm{C} \mathrm{db}$ & 0.8 & SS-EN ISO 18122:2015 \\
fixed carbon & 0.9 & calculated
\end{tabular}

\begin{tabular}{lcl} 
& ultimate analysis (wt \%) \\
\hline carbon $(\mathrm{C}), \mathrm{db}$ & 49.1 & SS-EN ISO 16948:2015 \\
hydrogen $(\mathrm{H}), \mathrm{db}$ & 6.1 & SS-EN ISO 16948:2015 \\
oxygen $(\mathrm{O}), \mathrm{db}$ & 43.8 & calculated \\
nitrogen $(\mathrm{N}), \mathrm{db}$ & 0.12 & SS-EN ISO 16948:2015 \\
sulphur (S), db & 0.026 & SS-EN ISO 16948:2015
\end{tabular}

${ }^{a} \mathrm{db}=$ dry basis.

deposition of coke in the catalyst and dealumination degrade the activity of the catalyst. ${ }^{16,17}$

Another development of a catalyst for the conversion of lignocellulose biomass is based on mesoporous materials, such as MCM-41. A study investigated the effect of employing MCM-41 in the catalytic pyrolysis process of lignocel from beech wood and Miscanthus. The results showed that a low $\mathrm{Si} /$ $\mathrm{Al}$ ratio of MCM-41 as well as the use of metal-containing catalysts, $\mathrm{Fe}-\mathrm{Al}-\mathrm{MCM}-41$ and $\mathrm{Cu}-\mathrm{Al}-\mathrm{MCM}-41$, promoted the production of phenol compounds. ${ }^{18}$ Another study showed that $\mathrm{Al}-\mathrm{MCM}-41$ not only increased the production of phenols but also lowered the corrosive acid concentrations. ${ }^{19}$ However, MCM-41 had a lesser ability to deoxygenate and resulted in a high amount of heavy aromatic products. ${ }^{20}$ Therefore, further developments and applications of catalyst are required to control the product distribution and selectivity in the process.

In previous studies, the potential of using $\mathrm{H}-\mathrm{ZSM}-5$ and $\mathrm{Al}-$ MCM-41 in a two-staged system of the mesoporous and microporous catalysts has been proved to improve the quality of bio-oil. $^{21,22}$ Other researchers ${ }^{23-26}$ also claimed that an addition of mesoporous and microporous catalysts into the pyrolysis process enhanced the production of aromatics and olefins.

A kinetic analysis is essential to design and establish efficient, safe, and reasonable processes, including a catalytic pyrolysis process to produce biofuel from lignocellulose biomass. Determination of the thermo-kinetic behavior of biomass allows a control of the decomposition mechanism of biomass as a function of pressure, temperature, and combustion. The kinetic parameters of reaction are necessary to predict the reaction behaviors and to optimize the process toward the desired products during the pyrolytic degradation process. The kinetic parameters of biomass pyrolysis depend not only on the feedstock composition, but also on the pyrolytic conditions, such as the decomposition temperature, heating rate, and the presence or absence of catalysts. ${ }^{27}$ Thermogravimetric analysis (TGA) is one of the tools to provide information on the kinetic reactions of the thermal degradation of biomass. ${ }^{5,28}$ Furthermore, information of biomass pyrolysis kinetics is important to evaluate biomass as a future feedstock for fuel or chemical production as well as for an efficient design and control of thermochemical processes. ${ }^{7}$

The development of hybrid micro-mesoporous material from $\mathrm{H}-\mathrm{ZSM}-5 / \mathrm{Al}-\mathrm{MCM}-41$ and its application for vacuum gas oil (VGO) pyrolysis was carried out by Coriolano et al. ${ }^{29}$ The model-free kinetic was applied to determine the activation energy of VGO alone and VGO with catalyst. It was found that the activation energy decreased with the use of hybrid catalysts. ${ }^{29}$ Nevertheless, there has been limited investigation on the proportion of H-ZSM-5 and Al-MCM-41 in the hybrid material.
Costa et al. ${ }^{30}$ synthesized the hybrid materials of Al-MCM41/ZSM-5. The thermogravimetry method was used to monitor the removal of the templates, cetyltrimethylammonium bromide (CTMA+) and tetrapropylammonium bromide (TPA+), from a nanostructured hybrid Al-MCM-41/ZSM-5 material. The kinetic model was used to evaluate the kinetic parameters of the surfactant decompositions from the optimized Al-MCM-41/ZSM-5 materials. However, no kinetic study on the catalytic pyrolysis of biomass using the catalyst mentioned was reported in their work.

Kinetic modeling for catalytic cracking of used palm oil and palm oil fatty acid mixture with composite MCM-41/ZSM-5 was investigated by Ooi et al. ${ }^{28}$ The results showed that the feedstock composition affected the product distribution and that the reaction rate parameters were dependent on the type of feedstock. ${ }^{28}$

Some researchers ${ }^{8,27,31-34}$ studied the thermal behavior of catalytic pyrolysis of biomass by physically mixing the biomass with the catalyst when performing thermogravimetry analysis experiments. Nevertheless, the kinetic study of lignocellulose catalytic pyrolysis using $\mathrm{H}-\mathrm{ZSM}-5$ and $\mathrm{Al}-\mathrm{MCM}-41$ as a mixed catalyst is lacking in the literature.

A previous study by the authors ${ }^{21}$ has primarily concentrated on the investigation of catalyst mixtures for favorable compound production, which include hydrocarbons, phenols, furan, and alcohols. In the present work, the pyrolysis kinetic behaviors, such as the activation energy $\left(E_{\mathrm{a}}\right)$, will be determined for TGA-pyrolyzed samples using the CoatsRedfern integral method. The catalytic pyrolysis of lignocellulosic biomass was investigated under an inert atmosphere using TGA to gain an overall understanding of the interactions between the biomass and the catalyst. Even though the catalytic pyrolysis kinetics have been reported, ${ }^{35-42}$ the catalytic pyrolysis of lignocellulose biomass with a mixed catalyst of HZSM-5 and Al-MCM-41 at different ratios as well as the quantification of benzene, toluene, and xylene (BTX) resulting from the process have never been proposed. Hence, this study would fill that specific knowledge gap of catalytic pyrolysis.

\section{MATERIALS AND METHODS}

Biomass Preparation and Characterization. Lignocellulose biomass from beech wood was used as a sample. The sample was provided by J. Rettenmaier \& Söhne GMBH + CO KG, Rosenberg, Germany. Before the experiments, the sample was ground to particle sizes ranging from 300 to $500 \mu \mathrm{m}$, in order to minimize the effect of heat conduction during the thermal decomposition process. ${ }^{43,44}$ Then, the sample was dried in an oven at $110^{\circ} \mathrm{C}$ overnight to reduce the water content. The proximate and ultimate analysis of the sample is presented in Table 1 .

Preparation and Characterization of Catalysts. The catalysts used for the TGA experiment were H-ZSM-5 and Al-MCM-41 and they were added as powders. The H-ZSM-5 powder was from Alfa Aesar, Germany, whereas the Al-MCM-41 powder was from the 
Nankai University Catalyst Plant in China. The catalysts were calcined in the muffle furnace at $550^{\circ} \mathrm{C}$ for $15 \mathrm{~h}$ and then dried in the oven at $110^{\circ} \mathrm{C}$ for $12 \mathrm{~h}$.

The $\mathrm{N}_{2}$ adsorption-desorption measurement was carried out on a Micromeritics ASAP 2020 instrument and the Brunauer-EmmettTeller (BET) method was performed to determine the surface area. The samples were outgassed at $250{ }^{\circ} \mathrm{C}$ for $3 \mathrm{~h}$ under vacuum prior to the measurement. The micropore volume was obtained from the $t$ plot method. The physicochemical properties of catalysts are shown in Table 2.

Table 2. Physicochemical Properties of H-ZSM-5 and AlMCM-41 Catalysts

\begin{tabular}{lccc}
\multicolumn{1}{c}{ catalyst } & $\begin{array}{c}\mathrm{Si} / \text { Al ratio } \\
(\mathrm{SAR})\end{array}$ & $\begin{array}{c}\text { BET surface area } \\
\left(\mathrm{m}^{2} \mathrm{~g}^{-1}\right)\end{array}$ & $\begin{array}{c}\text { micropore volume } \\
\left(\mathrm{cm}^{3} \mathrm{~g}^{-1}\right)\end{array}$ \\
\hline HZSM-5 & 30 & $311.77 \pm 5.53$ & $0.1458 \pm 0.0089$ \\
Al-MCM-41 & 25 & $943.91 \pm 46.50$ & \\
\hline
\end{tabular}

TGA Experimental Procedure. The samples for the TGA experiments were prepared at a fixed biomass loading and catalyst mass loading ratio (biomass/catalyst) of $1: 1$ and with a total mass of $60 \mathrm{mg}$. For noncatalytic experiments using lignocellulose biomass, the sample was marked as L. Furthermore, for catalytic pyrolysis experiments, the ratio of H-ZSM-5 and Al-MCM-41 was varied and labeled as follows: LH (1:0), LHA-71 (7:1), LHA-31 (3:1), LHA11 (1:1), and LA (0:1). Prior to each run, the sample and catalysts were mixed thoroughly to ensure a good uniformity of the sample mixture.

The following temperature program was used. From an ambient temperature to $110{ }^{\circ} \mathrm{C}$, at a heating rate of $10{ }^{\circ} \mathrm{C} / \mathrm{min}$, for sample drying (moisture removal); isothermal drying at $110^{\circ} \mathrm{C}$, for $10 \mathrm{~min}$ (until constant mass was reached); temperature raising from 110 to $900{ }^{\circ} \mathrm{C}$ (for pyrolysis and a subsequent release of volatiles) at different heating rates $\left(10,20,30,50{ }^{\circ} \mathrm{C} / \mathrm{min}\right)$, and isothermal transformation at $900{ }^{\circ} \mathrm{C}$ for $10 \mathrm{~min}$ (to enhance the devolatilization process and production of char). From an ambient temperature to $900{ }^{\circ} \mathrm{C}$, argon at a flow rate of $50 \mathrm{~mL} \mathrm{~min}^{-1}$ was used to maintain the reacting atmosphere inert. The mass loss and mass loss rate were recorded online as functions of time and temperature.

Kinetic Study. The rate of conversion at a constant rate of temperature change may be expressed by the following relationship

$$
\frac{\mathrm{d} x}{\mathrm{~d} y}=\beta \frac{\mathrm{d} x}{\mathrm{~d} T}=K(T) f(x)
$$

where $\mathrm{d} x / \mathrm{d} y$ is the rate of conversion and $x$ expresses the degree of advance, $\beta=\mathrm{d} T / \mathrm{d} t$ is the rate of temperature change, whereas $f(x)$ and $K(T)$ are functions of conversion and temperature, respectively.

An Arrhenius equation was used to model the temperature dependence of the weight loss rate as follows

$$
K(T)=A \exp \left(-\frac{E_{\mathrm{a}}}{R T}\right)
$$

where $E_{a} A$, and $R$ are the apparent activation energy, pre-exponential factor, and gas constant, respectively.

Coats-Redfern is an integral method, which involves the thermal degradation mechanism. The integration and assumptions used to define eq 2 are described elsewhere, ${ }^{45}$ but it can be expressed as follows

$$
\ln \frac{g(x)}{T^{2}}=\ln \frac{A R}{\beta E_{\mathrm{a}}}-\frac{E_{\mathrm{a}}}{R T}
$$

The kinetic parameters for this study were determined using the Avrami mechanism expressing first-order chemical reactions (A1, F1) which may be expressed as follows

$$
g(x)=-\ln (1-\alpha)
$$

Bench-Scale Reactor System. A fixed bed reactor equipped with oil condensers and a gas collection bag (Figure 1) was used for the

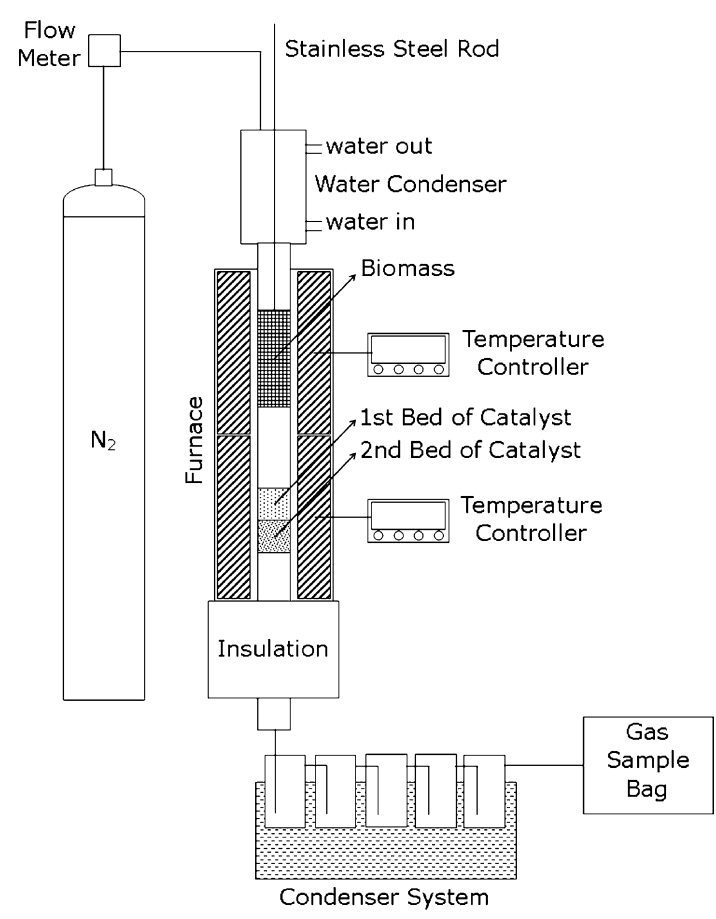

Figure 1. Catalytic pyrolysis reactor schematic diagram.

bench-scale catalytic pyrolysis processes. First, the reactor was heated up to the desirable temperature. Thereafter, a biomass sample of $10 \mathrm{~g}$ was employed in the reactor with a total catalyst mass of $10 \mathrm{~g}$. The ratio of the sample to catalyst was maintained at 1:1.

Second, the unreacted biomass was pushed to the middle of the furnace from the water condenser tube by using a stainless-steel rod. The pyrolysis process was carried out for $30 \mathrm{~min}$ with nitrogen as a carrier gas. Next, after the process was completed, the reacted biomass was pulled from the middle of the furnace back to the water condenser tube, following a purge of the reactor with $350 \mathrm{~mL} \mathrm{~min}^{-1}$ of nitrogen for another $15 \mathrm{~min}$ at reaction temperature to strip any remaining products from the catalyst. The experiments were run at variable temperatures of 400,500 , and $600{ }^{\circ} \mathrm{C}$.

Five condensers were prepared in the isopropanol bath and maintained at a temperature of $-15{ }^{\circ} \mathrm{C}$ to collect the condensable liquid products, whereas the noncondensable gases were collected in a Tedlar gas sample bag. Thereafter, the liquid product was analyzed using gas chromatography-mass spectrometry (GC-MS).

GC-MS Calibration for Quantifying BTX. An HP-5 column 60 $\mathrm{m} \times 0.25 \mathrm{~mm} \times 0.25 \mu \mathrm{m}$ was installed before the calibrating process. A pre-testing was conducted in order to prevent leaking, followed by a conditioning of the column. An injection test was done by using dichloromethane (DCM) and the calibration could be processed when only one peak of DCM was shown in the chromatogram.

A single-point internal standard was chosen as the method for calibrating the GC-MS. A calibration ampule of $\mathrm{P}-\mathrm{I}-\mathrm{A}-\mathrm{N}-\mathrm{O}$ (paraffin-isoparaffin-aromatics-naphthenes-olefins) detailed hydrocarbon analysis from the LGC Group, Germany, was used as a calibration solution. The calibration was carried out with five different concentrations to draw the calibration curve. An $R$-squared value of 0.990 from the calibration curve was taken as evidence of the validity of the calibration method.

\section{RESULTS AND DISCUSSIONS}

Influence of Catalyst Ratio Loading on Biomass Degradation. Figure 2a shows the TGA analysis for the noncatalytic and catalytic pyrolysis of lignocellulose biomass, 


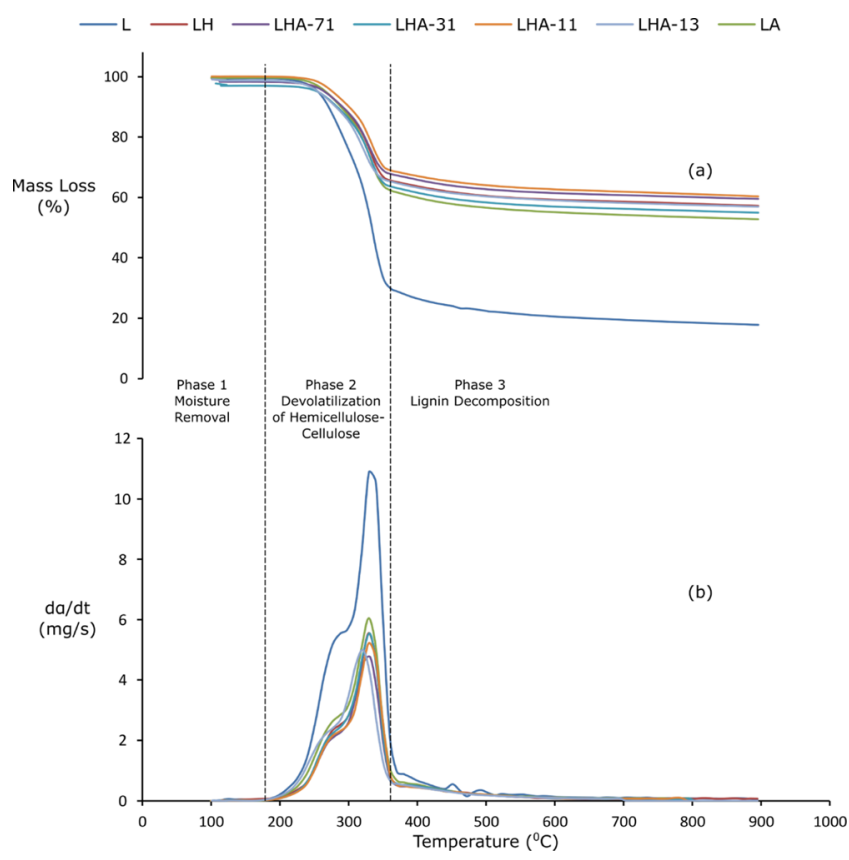

Figure 2. TGA (a) and DTG (b) plots for noncatalytic and catalytic pyrolysis of lignocellulose biomass from TGA experiments at the heating rate of $10 \mathrm{~K} \mathrm{~min}^{-1}$. The ratio of H-ZSM-5 and Al-MCM-41 was varied and labeled as follows: LH (1:0), LHA-71 (7:1), LHA-31 (3:1), LHA-11 (1:1), and LA (0:1).

whereas Figure $2 \mathrm{~b}$ presents the DTG profiles. Three phases of thermal degradations of lignocellulose biomass were observed in the TGA-DTG curves. Drying and evaporation of light components took place during phase 1 (25-180 $\left.{ }^{\circ} \mathrm{C}\right)$, devolatilization of hemicellulose and cellulose components during phase $2\left(180-360{ }^{\circ} \mathrm{C}\right)$, and lignin decomposition during phase $3\left(360-900^{\circ} \mathrm{C}\right)$. The solid residues were formed at $900{ }^{\circ} \mathrm{C}$.

In phase 1 , it is observed that all samples have evolved at a different mass loss, as shown in Figure 3. During phase 1, all

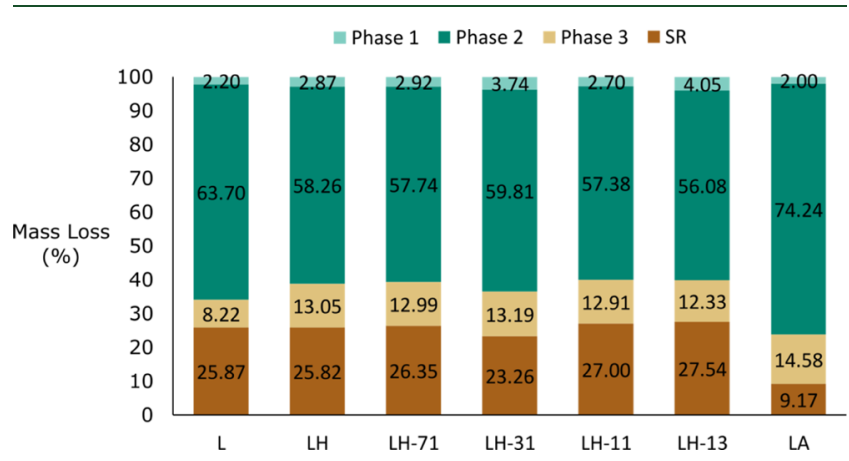

Figure 3. Mass loss of lignocellulose biomass from TGA experiments at a heating rate of $10 \mathrm{~K} \mathrm{~min}^{-1}$.

the moisture content, mainly composed of a water compound $\left(\mathrm{H}_{2} \mathrm{O}\right)$, was evaporated. Prior to TGA experiments, lignocellulose biomass and catalysts were dried in the oven. Hence, the mass loss in phase 1 was less than $5 \%$.

A further degradation in phase 2 can be divided into two sections of degradation, which are a hemicellulose degradation followed by a cellulose degradation. Similar patterns of curves were observed in all samples with hemicellulose degradation for the first peak and cellulose degradation for the second peak.
The degradation temperatures for both peaks were also similar, which were from 180 to $360{ }^{\circ} \mathrm{C}$. This is supported by the results from the study of Jankovic B. Ž. and Janković M. M. ${ }^{42}$ which revealed that a rapid mass loss of beech wood pyrolysis was observed in the temperature range of $280-320{ }^{\circ} \mathrm{C} .^{42}$ This is also a temperature range for cellulose and hemicellulose decomposition. ${ }^{46} \mathrm{Lu}$ et al. ${ }^{27}$ investigated the catalytic pyrolysis of wheat straws with a solid acid catalyst and found that the primary decomposition reactions occurred in the temperature range from 200 to $350{ }^{\circ} \mathrm{C}$, which agrees well with the present results. However, the degradation rates were different for the peak of each sample. Accordingly, the catalyst mixture ratios do not influence the degradation temperature of lignocellulose biomass. Nevertheless, they have a significant effect on the degradation rates.

By changing the ratio of H-ZSM-5 and Al-MCM-41 in the catalyst mixture, the peak shifted, as shown in Figure $2 \mathrm{~b}$. From Figure 3, it can be seen that the mass losses for noncatalytic pyrolysis amount to $63.70 \%$, whereas for catalytic pyrolysis using H-ZSM-5 and Al-MCM-41 the mass losses are 58.26 and $74.24 \%$, respectively. The low mass loss percentage in the experiment with H-ZSM-5 can be due to its microporous structure and low BET surface area $\left(315 \mathrm{~m}^{2} \mathrm{~g}^{-1}\right)$. Khan et al. ${ }^{47}$ reported similar results, wherein the diffusion of bulky reactants and products into and out of the catalyst pores are inevitably restricted by the microporous channels in zeolites. Seo et al. ${ }^{48}$ also reported that the use of a microporous catalyst with low BET surface increases the char production, ${ }^{48}$ leading to retarded reaction rates or catalyst deactivation. ${ }^{47}$ Contrarily, the mesoporosity of $\mathrm{Al}-\mathrm{MCM}-41$ promotes the conversion of the large molecules from a lignocellulose biomass.

LH-13 (56.08\%), LH-11 (57.38\%), and LH-71 (57.74\%) show an increment line in mass loss percentage. Yet, the values are low compared to the percentage of mass loss when using $\mathrm{H}-\mathrm{ZSM}-5$ or Al-MCM-41. The decrease in the Al-MCM-41 and H-ZSM-5 weight load for the LH-13, LH-11, and LH-71 samples is assumed to be a factor that causes the decrement of the mass loss percentage. An exception occurred in the LH-31 sample, which gives a mass loss of $59.81 \%$. The loss percentage of the LH-31 sample is higher than that of H-ZSM-5 but lower than that of $\mathrm{Al}-\mathrm{MCM}-41$. At this ratio, the catalyst works best in cracking hemicellulose and cellulose compared to other mixture catalysts. The utilization of microporous H-ZSM-5 and mesoporous Al-MCM-41 enhances the accessibility ${ }^{49}$ and the mass transport of molecules, yet maintains the intrinsic shape selectivity of zeolite microporosity. ${ }^{47}$

Lignin was gradually degraded at a higher temperature, as there is no peak observed from the DTG plot. The trend of mass loss for phase 3 is close to that of phase 2. The LA sample was found to have the highest mass loss compared to other samples, whereas LH-13, LH-11, and LH-71 had lower mass loss percentages compared to LA and LH. The best interaction of H-ZSM-5 and Al-MCM-41 might be observed in the LH31 sample.

For pyrolysis of lignin, the scission of aliphatic groups begins at $280^{\circ} \mathrm{C}$, followed by the scission of aromatic parts at $380^{\circ} \mathrm{C}$, and the condensation of carbon in the char at $460{ }^{\circ} \mathrm{C}$. However, when hemicellulose and cellulose are present in the pyrolysis process, there is a shift in the degradation temperatures. ${ }^{50}$ Because of its complex structure, lignin decomposes slower over a broader temperature range of 200-500 ${ }^{\circ} \mathrm{C}$ than hemicellulose and cellulose. Hence, the DTG peak of lignin shows a wide and flat sloping baseline, 
Table 3. Kinetics Determined with the Coats-Redfern First-Order Equation Based on the Data in TGA-DTG Curves of Phase $2\left(180-360^{\circ} \mathrm{C}\right)$

\begin{tabular}{|c|c|c|c|c|c|c|c|c|}
\hline \multirow[b]{3}{*}{ sample } & \multicolumn{8}{|c|}{ kinetic parameter } \\
\hline & \multicolumn{2}{|c|}{$10 \mathrm{~K} \mathrm{~min}^{-1}$} & \multicolumn{2}{|c|}{$20 \mathrm{~K} \mathrm{~min}^{-1}$} & \multicolumn{2}{|c|}{$30 \mathrm{~K} \mathrm{~min}^{-1}$} & \multicolumn{2}{|c|}{$50 \mathrm{~K} \mathrm{~min}^{-1}$} \\
\hline & $E_{\mathrm{a}}\left(\mathrm{kJ} \mathrm{mol} \mathrm{m}^{-1}\right)$ & $R^{2}$ & 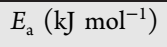 & $R^{2}$ & $E_{\mathrm{a}}\left(\mathrm{kJ} \mathrm{mol}^{-1}\right)$ & $R^{2}$ & $E_{\mathrm{a}}\left(\mathrm{kJ} \mathrm{mol}{ }^{-1}\right)$ & $R^{2}$ \\
\hline $\mathrm{L}$ & 134.64 & 0.9906 & 82.26 & 0.9930 & 55.03 & 0.9563 & 45.87 & 0.9980 \\
\hline $\mathrm{LH}$ & 116.70 & 0.9976 & 83.01 & 0.9974 & 65.79 & 0.9962 & 61.27 & 0.9777 \\
\hline LH-71 & 116.98 & 0.9979 & 81.15 & 0.9988 & 72.46 & 0.9916 & 62.77 & 0.9909 \\
\hline LH-31 & 126.12 & 0.9969 & 76.71 & 0.9989 & 73.21 & 0.9877 & 69.02 & 0.9902 \\
\hline LH-11 & 133.96 & 0.9989 & 76.70 & 0.9947 & 82.88 & 0.9963 & 27.59 & 0.9859 \\
\hline LH-13 & 125.91 & 0.9971 & 77.12 & 0.9921 & 91.21 & 0.9615 & 56.65 & 0.9807 \\
\hline LA & 127.69 & 0.9963 & 73.80 & 0.9911 & 69.46 & 0.9753 & 48.75 & 0.9994 \\
\hline
\end{tabular}

which is different from the sharper DTG peaks of hemicellulose and cellulose. Lignin is losing only $40 \%$ of its initial mass below $700{ }^{\circ} \mathrm{C}$ and around $67 \%$ at $850{ }^{\circ} \mathrm{C} .{ }^{51}$ Another finding by Yang et al. ${ }^{52}$ showed that $30-40 \%$ of lignin remained un-volatized at $800{ }^{\circ} \mathrm{C}$ because of the aromatic structure condensation, which led to the formation of char. ${ }^{52}$ Therefore, the aim on the current study was to determine mass loss up to $900{ }^{\circ} \mathrm{C}$.

After Phase 3, the leftover biomass materials were considered as solid residual (SR), which had not been degraded at the temperature of $900{ }^{\circ} \mathrm{C}$. Yet, the catalyst mixtures of H-ZSM-5 and Al-MCM-41 on lignocellulose biomass influenced the amount of SR. Also, the solid can be regarded as a char yield percentage. The LH-13 sample produced the highest SR at $27.54 \%$ after $900{ }^{\circ} \mathrm{C}$ compared to other samples. Contrarily, the LA sample had SR accounting for $9.17 \%$, which was the lowest yield of SR compared to others (23.26-27.54\%).

Kinetic Parameters of Lignocellulose Biomass. On the basis of the data obtained from TGA pyrolysis and catalytic pyrolysis experiments of lignocellulose biomass, the activation energy $\left(E_{\mathrm{a}}\right)$ and frequency factor $(A)$ were calculated, as shown in Table 3. The aforementioned kinetic parameters were determined by employing the Coats-Redfern integral method and using a first-order equation (A1, F1). As the biomass catalytic pyrolysis process undergoes multiple step reactions, the Coats and Redfern model is found to be an appropriate model for the determination of thermogravimetric experimental results. ${ }^{27,53}$ A study by Boukaous et al. ${ }^{39}$ and Abdullah et al. ${ }^{54}$ supported this study. They found that the kinetics of beech wood followed the first-order kinetics model. As the lignocellulose material used for this study originated from beech wood, the first-order kinetics model (A1, F1) was adopted to describe the experimental data. Additionally, Sharp and Wentworth revealed that the Coats and Redfern method has high accuracies and is appropriate to use when evaluating the kinetic parameters. ${ }^{55}$

The Arrhenius plot, $\ln (-\ln (1-\alpha))$ as a function of $1 / T$, was plotted at different heating rates of $10,20,30$, and $50 \mathrm{~K}$ $\mathrm{min}^{-1}$. Later, the activation energy was calculated by using the slope of the plot. The kinetic parameters were only determined during phase $2\left(180-360{ }^{\circ} \mathrm{C}\right)$ as the highest volatile mass loss was found in phase 2 as an active pyrolysis zone compared to phases 1 and 3. The kinetic analysis was done for noncatalytic lignocellulose biomass (L) and compared to catalytic samples (LH, LH-71, LH-31, LH-11, LH-13, and LA) in phase 2. The linearity characteristics $\left(R^{2}\right)$ are used to determine the accuracy of the Arrhenius plot.
In the present study, the kinetic analysis of the TGA pyrolysis and catalytic pyrolysis showed that they have positive activation energies. The catalyst is commonly found to lower the activation energy of the process. For heating rates of 10 and $20 \mathrm{~K} \mathrm{~min}^{-1}$, nearly all the experiments using catalysts show 0.5-13.0\% lower activation energies compared to experiments without using catalysts. On the contrary, during heating rates of 30 and $50 \mathrm{~K} \mathrm{~min}^{-1}$, most of the catalyst samples have 6.3$66.0 \%$ higher activation energies compared to the noncatalyst sample. The higher activation energies from LH, LH-71, LH31, LH-11, LH-13, and LA might be due to the deposition of coke in the internal pore passage and pore mouth of the catalyst. Consequently, the activation energy increased because of the production of coke. The studies by Goenka et al. ${ }^{56}$ and Balasundram et al. ${ }^{57}$ support the present results, showing higher activation energies for catalytic pyrolysis of biomass compared to noncatalytic pyrolysis. Nonetheless, it should be noted that the activation energy of $\mathrm{L}\left(135 \mathrm{~kJ} \mathrm{~mol}^{-1}\right)$ at the heating rate of $10 \mathrm{~K} \mathrm{~min}^{-1}$ is in agreement with results reported by Di Blasi et al. ${ }^{36}\left(125-157 \mathrm{~kJ} \mathrm{~mol}^{-1}\right)$ and Reina et al. $^{58}\left(117-136 \mathrm{~kJ} \mathrm{~mol}^{-1}\right)$.

Further, as seen from Table 3, the activation energy of the samples, in either noncatalytic or catalytic pyrolysis, decreases as the heating rate increases. The difficulty of the catalytic pyrolysis reaction could be reflected by comparing the value of the derived activation energies, which implies that the smaller the activation energy the easier a catalytic pyrolysis reaction takes place. This finding is inconsistent with the result found by Wang et al. ${ }^{59}$ in their TGA of catalytic pyrolysis of biomass, sugar canes, and beets. However, they used another solid catalyst, namely $\mathrm{CaO}^{59}$ The decrease of the activation energy with an increased heating rate can be explained as follows. A ten-degree increase in temperature is supposed to double the rate of the chemical reaction. The increase in the temperature of the sample may be less than 10 degrees, which implies that the rate of the chemical reaction may also be less than doubled. Consequently, a low activation energy is achieved. Further, a faster heating rate corresponds to a larger deviation from equilibrium and a lower activation energy. Quan et al. ${ }^{60}$ also reported that a larger temperature gradient between the surface and inner part of the biomass particles is attributed to an increase in heating rate. Dingcheng et al. ${ }^{61}$ found that the increase of the heating rate influenced the decreased value of the activation energy in char samples, which is in good agreement with the results of the present study. Additionally, Chen ${ }^{62,63}$ stated that the mechanism of a solid phase reaction is usually complicated and not well understood. Most of the mechanisms are assumed to be controlled by diffusion and affected by some factors, including the heating rate. ${ }^{62,63}$ This 
study indicates that the heating rates have a significant effect on the reactions that occur during catalytic pyrolysis. A heating rate of $10 \mathrm{~K} \mathrm{~min}^{-1}$ and up to $20 \mathrm{~K} \mathrm{~min}^{-1}$ was found to be an optimum level to enhance the rate of decomposition and to prevent the repolymerization reactions of coke formation.

Influence of Catalyst Ratio Loading on BTX Yields. As the sample loading in the TGA was very small $(\sim 60 \mathrm{mg})$, the evolved gases were limited to performing a quantitative analysis. Thus, the experiments with a higher sample loading were carried out in a fixed bed reactor. Figure 5 shows the effect of the catalyst ratio loading on the yields of BTX. The highest percentages of BTX were achieved by employing a single H-ZSM-5 catalyst during the pyrolysis of lignocellulose biomass. The mass percentage of BTX present in the catalytic pyrolysis vapor decreased with a decreased H-ZSM-5 amount in the catalyst mixture, except for the LH-31 sample. This finding confirms the results from the thermogravimetric experiments in the previous section, which showed that a $\mathrm{H}$ ZSM-5 and Al-MCM-41 ratio of 3:1 worked best in cracking the biomass molecules. Although the values of BTX in LH-31 was lower than in $\mathrm{LH}$, a previous study showed that the favorable compounds in the biofuel that resulted from LH-31 exceeded the quality of biofuel from a process using a single $\mathrm{H}$ ZSM-5 catalyst. ${ }^{21}$ Among the catalytic pyrolysis samples, the process with a single $\mathrm{Al}-\mathrm{MCM}-41$ catalyst resulted in the lowest BTX yields.

The selectivity of benzene and toluene decreased when the amount of H-ZSM-5 in the catalyst mixture was reduced. However, an increased amount of Al-MCM-41 in the mixture led to the formation of xylene. This can be seen from the $0.68-4.41 \%$ higher mass percentages of xylene compared to the percentages of toluene from LH-13, LH-11, LH-31, and LH-71. A study by Jackson et al. ${ }^{64}$ supports the results of the present study. A high selectivity of BTX was observed in catalytic pyrolysis of lignin when using HZSM-5, whereas the process involving $\mathrm{Al}-\mathrm{MCM}-41$ resulted in a low amount of BTX. $^{64}$ The present study provides a pathway of shifting the product selectivity of biomass catalytic pyrolysis by mixing the H-ZSM-5 and Al-MCM-41 catalysts to achieve desirable product proportions (Figure 4).

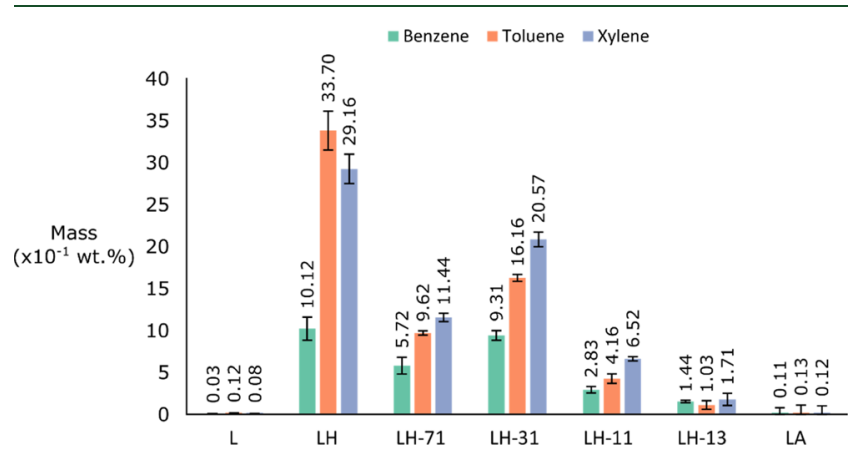

Figure 4. Effect of catalyst ratio loading on BTX yields.

Influence of Reaction Temperature on BTX Yields.

The catalytic pyrolysis of lignocellulose biomass was carried out at temperatures ranging from 400 to $600{ }^{\circ} \mathrm{C}$ to determine the optimum temperature when using a H-ZSM-5 and $\mathrm{Al}-$ MCM-41 catalyst ratio of 3:1. The yields of BTX produced from the process are presented in Figure 5. At temperatures of 400,500 , and $600{ }^{\circ} \mathrm{C}$, BTX levels of $0.49,0.44$, and 0.74 wt $\%$ were obtained, respectively. Besides an increase of the

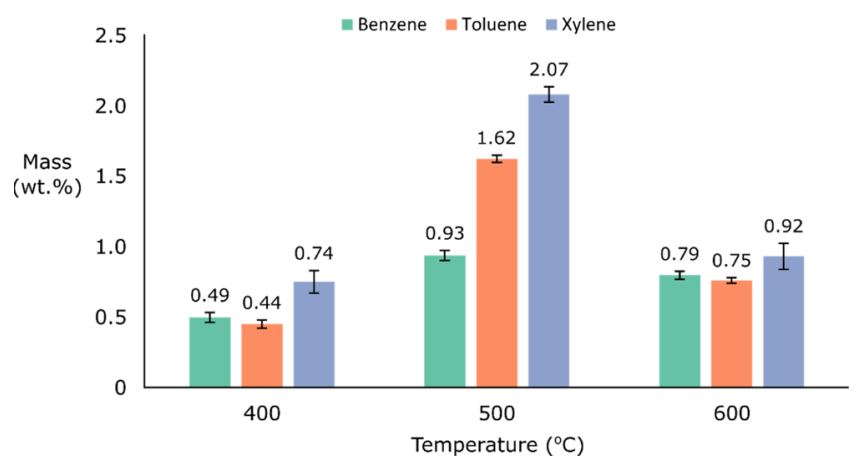

Figure 5. Effect of temperature on the catalytic pyrolysis of lignocellulose biomass when using a H-ZSM-5/Al-MCM-41 catalyst ratio of $3: 1$.

temperature, the yields of BTX rose and reached, in the best cases, 0.93 wt \% of benzene, $1.62 \mathrm{wt} \%$ of toluene, and $2.07 \mathrm{wt}$ $\%$ of xylene. However, increasing the temperature to $600{ }^{\circ} \mathrm{C}$ had a reverse effect on the BTX yields. The mass of benzene decreased to 0.79 wt $\%$, whereas the mass of toluene and xylene dropped to 0.75 and 0.92 wt \%, respectively. The area percentage of the other compounds are presented elsewhere. ${ }^{21}$

The results in this study agree with the earlier results by Melligan et al., ${ }^{65}$ namely that the temperature influenced the product selectivity toward BTX. They observed an increase of the benzene and toluene levels during catalytic pyrolysis of biomass using Ni-MCM-41 as the temperature rose from 300 to $450{ }^{\circ} \mathrm{C} .{ }^{65}$ Very similar results were found for other catalysts at a higher temperature. ${ }^{66}$ The present study suggests a temperature of $500{ }^{\circ} \mathrm{C}$ as the optimum temperature for catalytic pyrolysis of lignocellulose biomass when using a $\mathrm{H}$ ZSM-5/Al-MCM-41 ratio of 3:1 to obtain the highest BTX yields of $0.93,1.62$, and $2.07 \%$, respectively.

\section{CONCLUSIONS}

The study set out to determine the thermal degradation behavior of lignocellulose biomass with different catalyst ratios between H-ZSM-5 and Al-MCM-41. Specifically, the investigated catalyst mixture ratios of $\mathrm{H}-\mathrm{ZSM}-5 / \mathrm{Al}-\mathrm{MCM}$ 41 were $7: 1,3: 1,1: 1$, and $1: 3$. The activation energy of the catalytic pyrolysis process as well as the yields of BTX in regard to different catalyst loadings and reaction temperatures were also investigated.

The main finding can be summarized as follows:

1 The results of the TGA show that three phases of thermal degradation of lignocellulose biomass could be observed. Drying and evaporation of light components took place during phase $1\left(25-180^{\circ} \mathrm{C}\right)$, devolatilization of hemicellulose and cellulose components during phase $2\left(180-360^{\circ} \mathrm{C}\right)$, and lignin decomposition during phase $3\left(360-900{ }^{\circ} \mathrm{C}\right)$. In addition, the solid residues were formed at $900{ }^{\circ} \mathrm{C}$. The mass losses for noncatalytic pyrolysis amount to $63.70 \%$, whereas for catalytic pyrolysis with $\mathrm{H}-\mathrm{ZSM}-5$ and $\mathrm{Al}-\mathrm{MCM}-41$ they are 58.26 and $74.24 \%$, respectively. The H-ZSM-5/AlMCM-41 ratio of 3:1 was found to work best in cracking hemicellulose and cellulose compared to other mixtures of catalysts.

2 During heating rates of 10 and $20 \mathrm{~K} \mathrm{~min}^{-1}$, nearly all the experiments using catalysts show $0.5-13.0 \%$ lower activation energies than those without using catalysts. 
On the contrary, during heating rates of 30 and $50 \mathrm{~K}$ $\mathrm{min}^{-1}$, most of the catalyst samples have $6.3-66.0 \%$ higher activation energies compared to the noncatalyst sample. The higher activation energies were attributed to the production of coke. The activation energies of samples, in either noncatalytic or catalytic pyrolysis, decreased as the heating rate increased. It is assumed that there was a deviation between the ambient and sample temperatures.

3 The catalyst mixture with different ratios of H-ZSM-5 and $\mathrm{Al}-\mathrm{MCM}-41$ influenced the selectivity toward obtaining BTX products. The high ratio of $\mathrm{H}-\mathrm{ZSM}-5$ in the catalyst mixture led to the formation of benzene and toluene. Furthermore, the higher the amount of $\mathrm{Al}-$ MCM-41 in the mixture, the higher the proportion of xylene compared to toluene. The activities of H-ZSM-5 and $\mathrm{Al}-\mathrm{MCM}-41$ attained the best interaction with the mixture ratio of $3: 1$, which resulted in 9.31 wt $\%$ of benzene, 16.16 wt $\%$ of toluene, and 20.57 wt $\%$ of xylene.

4 The temperature of $500{ }^{\circ} \mathrm{C}$ appeared to be the optimum temperature for catalytic pyrolysis of lignocellulose biomass with a H-ZSM-5/Al-MCM-41 ratio of 3:1, with respect to BTX yields. Specifically, it resulted in the production of $0.93 \mathrm{wt} \%$ benzene, $1.62 \mathrm{wt} \%$ toluene, and 2.07 wt $\%$ xylene.

\section{AUTHOR INFORMATION}

\section{Corresponding Author}

*E-mail: dkra@kth.se.

\section{ORCID}

Devy K. Ratnasari: 0000-0002-8238-3206

Notes

The authors declare no competing financial interest.

\section{ACKNOWLEDGMENTS}

This work was supported by the Swedish Energy AgencyEnergimydigheten - under the ERA-NET Bioenergy program no. 43911-1. A discussion with Nanta Sophonrat and Ilman Nuran Zaini on the conception and design of the study was greatly appreciated.

\section{REFERENCES}

(1) BBC. Reasons for increase in demand of energy https://www. bbc.com/bitesize/guides/zpmmmp3/revision/1 (accessed Jan 3, 2019).

(2) McLamb, E. Fossil Fuels vs. Renewable Energy Resources http://www.ecology.com/2011/09/06/fossil-fuels-renewable-energyresources/ (accessed Jan 3, 2019).

(3) Amutio, M.; Lopez, G.; Aguado, R.; Artetxe, M.; Bilbao, J.; Olazar, M. Kinetic Study of Lignocellulosic Biomass Oxidative Pyrolysis. Fuel 2012, 95, 305-311.

(4) Sheth, P. N.; Babu, B. V. Kinetic Modeling of the Pyrolysis of Biomass. In Proceedings of National Conference on Environmental Conservation (NCEC-2006); Babu, B. V., Ramakrishna, V., Eds.; Pilani: India, 2006; pp 453-458.

(5) Becidan, M.; Várhegyi, G.; Hustad, J. E.; Skreiberg, Ø. Thermal Decomposition of Biomass Wastes. A Kinetic Study. Ind. Eng. Chem. Res. 2007, 46, 2428-2437.

(6) Lin, Y.-C.; Huber, G. W. The Critical Role of Heterogeneous Catalysis in Lignocellulosic Biomass Conversion. Energy Environ. Sci. 2009, 2, 68-80.

(7) Ceylan, S.; Topçu, Y. Pyrolysis Kinetics of Hazelnut Husk Using Thermogravimetric Analysis. Bioresour. Technol. 2014, 156, 182-188.
(8) Balasundram, V.; Ibrahim, N.; Kasmani, R. M.; Hamid, M. K. A.; Isha, R.; Hasbullah, H.; Ali, R. R. Thermogravimetric Catalytic Pyrolysis and Kinetic Studies of Coconut Copra and Rice Husk for Possible Maximum Production of Pyrolysis Oil. J. Clean. Prod. 2017, 167, 218-228.

(9) Baniasadi, M.; Tugnoli, A.; Cozzani, V. Optimization of Catalytic Upgrading of Pyrolysis Products. Chem. Eng. Trans. 2016, 49, 265270 .

(10) Brown, R. C.; Harlow, S. Fast Pyrolysis Efficiently Turns Biomass into Renewable Fuels https://articles.extension.org/pages/ 72722 /fast-pyrolysis-efficiently-turns-biomass-into-renewable-fuels (accessed April 15, 2019).

(11) Gayubo, A. G.; Aguayo, A. T.; Atutxa, A.; Aguado, R.; Bilbao, J. Transformation of Oxygenate Components of Biomass Pyrolysis Oil on a HZSM-5 Zeolite. I. Alcohols and Phenols. Ind. Eng. Chem. Res. 2004, 43, 2610-2618.

(12) Caruso, W.; Sorenson, D.; Mossa, A. Alternative Energy Technologies: High Tech Solutions for Urban Carbon Reduction; 2006.

(13) Zhang, L.; Liu, R.; Yin, R.; Mei, Y. Upgrading of Bio-Oil from Biomass Fast Pyrolysis in China: A Review. Renew. Sustain. Energy Rev. 2013, 24, 66-72.

(14) Rezaei, P. S.; Shafaghat, H.; Daud, W. M. A. W. Production of Green Aromatics and Olefins by Catalytic Cracking of Oxygenate Compounds Derived from Biomass Pyrolysis: A Review. Appl. Catal., A 2014, 469, 490-511.

(15) Vitolo, S.; Bresci, B.; Seggiani, M.; Gallo, M. G. Catalytic Upgrading of Pyrolytic Oils over HZSM-5 Zeolite: Behaviour of the Catalyst When Used in Repeated Upgrading-regenerating Cycles. Fuel 2001, 80, 17-26.

(16) Tan, S.; Zhang, Z.; Sun, J.; Wang, Q. Recent Progress of Catalytic Pyrolysis of Biomass by HZSM-5. Chin. J. Catal. 2013, 34, 641-650.

(17) Grams, J.; Ruppert, A. Development of Heterogeneous Catalysts for Thermo-Chemical Conversion of Lignocellulosic Biomass. Energies 2017, 10, 545.

(18) Antonakou, E.; Lappas, A.; Nilsen, M. H.; Bouzga, A.; Stöcker, M. Evaluation of Various Types of Al-MCM-41 Materials as Catalysts in Biomass Pyrolysis for the Production of Bio-Fuels and Chemicals. Fuel 2006, 85, 2202-2212.

(19) Iliopoulou, E. F.; Antonakou, E. V.; Karakoulia, S. A.; Vasalos, I. A.; Lappas, A. A.; Triantafyllidis, K. S. Catalytic Conversion of Biomass Pyrolysis Products by Mesoporous Materials: Effect of Steam Stability and Acidity of Al-MCM-41 Catalysts. Chem. Eng. J. 2007, 134, 51-57.

(20) Wang, Y. M.; Wang, J. Catalytic Performances of HZSM-5, $\mathrm{NaY}$ and MCM-41 in Two-Stage Catalytic Pyrolysis of Pinewood. IOP Conf. Ser. Earth Environ. Sci. 2016, 40, 012015.

(21) Ratnasari, D. K.; Yang, W.; Jönsson, P. G. Two-Stage Ex-Situ Catalytic Pyrolysis of Lignocellulose for the Production of GasolineRange Chemicals. J. Anal. Appl. Pyrolysis 2018, 134, 454-464.

(22) Ratnasari, D. K.; Nahil, M. A.; Williams, P. T. Catalytic Pyrolysis of Waste Plastics Using Staged Catalysis for Production of Gasoline Range Hydrocarbon Oils. J. Anal. Appl. Pyrolysis 2017, 124, 631-637.

(23) Marker, T. L.; Petri, J. A. Gasoline and Diesel Production from Pyrolytic Lignin Produced from Pyrolysis of Cellulosic Waste. U.S. Patent 7,578,927 B2, 2009.

(24) Adjaye, J. D.; Katikaneni, S. P. R.; Bakhshi, N. N. Catalytic conversion of a biofuel to hydrocarbons: effect of mixtures of HZSM5 and silica-alumina catalysts on product distribution. Fuel Processing Technology 1996, 48, 115-143.

(25) Zhang, H.; Xiao, R.; Jin, B.; Xiao, G.; Chen, R. Biomass Catalytic Pyrolysis to Produce Olefins and Aromatics with a Physically Mixed Catalyst. Bioresour. Technol. 2013, 140, 256-262.

(26) Zhang, H.; Zheng, J.; Xiao, R.; Jia, Y.; Shen, D.; Jin, B.; Xiao, G. Study on Pyrolysis of Pine Sawdust with Solid Base and Acid Mixed Catalysts by Thermogravimetry-Fourier Transform Infrared Spectroscopy and Pyrolysis-Gas Chromatography/Mass Spectrometry. Energy Fuels 2014, 28, 4294-4299. 
(27) Lu, C.; Song, W.; Lin, W. Kinetics of Biomass Catalytic Pyrolysis. Biotechnol. Adv. 2009, 27, 583-587.

(28) Ooi, Y.-S.; Zakaria, R.; Mohamed, A. R.; Bhatia, S. Catalytic Cracking of Used Palm Oil and Palm Oil Fatty Acids Mixture for the Production of Liquid Fuel: Kinetic Modeling. Energy Fuels 2004, 18, $1555-1561$.

(29) Coriolano, A. C. F.; Silva, C. G. C.; Costa, M. J. F.; Pergher, S. B. C.; Caldeira, V. P. S.; Araujo, A. S. Development of HZSM-5/ AlMCM-41 Hybrid Micro-mesoporous Material and Application for Pyrolysis of Vacuum Gasoil. Microporous Mesoporous Mater. 2013, 172, 206-212.

(30) Costa, M. J. F.; Araujo, A. S.; Silva, E. F. B.; Farias, M. F.; Fernandes, V. J.; d'Amorim Santa-Cruz, P.; Pacheco, J. G. A. ModelFree Kinetics Applied for the Removal of CTMA+ and TPA+ of the Nanostructured Hybrid AlMCM-41/ZSM-5 Material. J. Therm. Anal. Calorim. 2011, 106, 767-771.

(31) Zhang, X.; Lei, H.; Zhu, L.; Zhu, X.; Qian, M.; Yadavalli, G.; $\mathrm{Wu}$, J.; Chen, $\mathrm{S}$. Thermal Behavior and Kinetic Study for Catalytic Co-Pyrolysis of Biomass with Plastics. Bioresour. Technol. 2016, 220, 233-238.

(32) Wang, L.; Lei, H.; Liu, J.; Bu, Q. Thermal Decomposition Behavior and Kinetics for Pyrolysis and Catalytic Pyrolysis of Douglas Fir. RSC Adv. 2018, 8, 2196-2202.

(33) Bu, Q.; Lei, H.; Qian, M.; Yadavalli, G. A Thermal Behavior and Kinetics Study of the Catalytic Pyrolysis of Lignin. RSC Adv. 2016, 6, 100700-100707.

(34) Coelho, A.; Costa, L.; Marques, M. M.; Fonseca, I. M.; Lemos, M. A. N. D. A.; Lemos, F. The Effect of ZSM-5 Zeolite Acidity on the Catalytic Degradation of High-Density Polyethylene Using Simultaneous DSC/TG Analysis. Appl. Catal., A 2012, 413-414, 183-191.

(35) Branca, C.; Di Blasi, C. Kinetics of the Isothermal Degradation of Wood in the Temperature Range 528-708 K. J. Anal. Appl. Pyrolysis 2003, 67, 207-219.

(36) Di Blasi, C.; Branca, C. Kinetics of Primary Product Formation from Wood Pyrolysis. Ind. Eng. Chem. Res. 2001, 40, 5547-5556.

(37) Diblasi, C. Modeling Chemical and Physical Processes of Wood and Biomass Pyrolysis. Prog. Energy Combust. Sci. 2008, 34, 47-90.

(38) Di Blasi, C. Comparison of Semi-Global Mechanisms for Primary Pyrolysis of Lignocellulosic Fuels. J. Anal. Appl. Pyrolysis 1998, 47, 43-64.

(39) Boukaous, N.; Abdelouahed, L.; Chikhi, M.; Meniai, A.-H.; Mohabeer, C.; Bechara, T. Combustion of Flax Shives, Beech Wood, Pure Woody Pseudo-Components and Their Chars: A Thermal and Kinetic Study. Energies 2018, 11, 2146.

(40) Rabacal, M.; Costa, M.; Vascellari, M.; Hasse, C. Kinetic Modelling of Sawdust and Beech Wood Pyrolysis in D rop Tube Reactors Using Advanced Predictive Models. Chem. Eng. Trans. 2014, 37, 79-84.

(41) Bonnefoy, F.; Gilot, P.; Prado, G. A Three-Dimensional Model for the Determination of Kinetic Data from the Pyrolysis of Beech Wood. J. Anal. Appl. Pyrolysis 1993, 25, 387-394.

(42) Janković, B. Z.; Janković, M. M. Pyrolysis of Pine and Beech Wood under Isothermal Conditions: The Conventional Kinetic Approach. Res. Chem. Intermed. 2015, 41, 2201-2219.

(43) Yang, L.; Chen, X.; Zhou, X.; Fan, W. The Pyrolysis and Ignition of Charring Materials under an External Heat Flux. Combust. Flame 2003, 133, 407-413.

(44) Hankalin, V.; Ahonen, T.; Raiko, R. On Thermal Properties of a Pyrolysing Wood Particle. 2009; p 16 p BT-Finnish-Swedish Flame Days 2009, January.

(45) Aboulkas, A.; El Harfi, k. Study of the kinetics and mechanisms of thermal decomposition of moroccan tarfaya oil shale and its kerogen. Oil Shale 2008, 25, 426.

(46) Shafizadeh, F. Pyrolytic Reactions and Products of Biomass. Fundamentals of Thermochemical Biomass Conversion; Springer Netherlands: Dordrecht, 1985; pp 183-217.

(47) Khan, W.; Jia, X.; Wu, Z.; Choi, J.; Yip, A. Incorporating Hierarchy into Conventional Zeolites for Catalytic Biomass Conversions: A Review. Catalysts 2019, 9, 127.
(48) Seo, Y.-H.; Lee, K.-H.; Shin, D.-H. Investigation of Catalytic Degradation of High-Density Polyethylene by Hydrocarbon Group Type Analysis. J. Anal. Appl. Pyrolysis 2003, 70, 383-398.

(49) Hernando, H.; Hernández-Giménez, A. M.; Ochoa-Hernández, C.; Bruijnincx, P. C. A.; Houben, K.; Baldus, M.; Pizarro, P.; Coronado, J. M.; Fermoso, J.; Čejka, J.; et al. Engineering the Acidity and Accessibility of the Zeolite ZSM-5 for Efficient Bio-Oil Upgrading in Catalytic Pyrolysis of Lignocellulose. Green Chem. 2018, 20, 34993511.

(50) Nassar, M. M.; MacKay, G. D. M. Mechanism of Thermal Decomposition of Lignin. Wood Fiber Sci. 1984, 16, 441-453.

(51) Brebu, M.; Vasile, C. Thermal Degradation of Lignin - A Review. Cellul. Chem. Technol. 2010, 44, 353-363.

(52) Yang, H.; Yan, R.; Chen, H.; Lee, D. H.; Zheng, C. Characteristics of Hemicellulose, Cellulose and Lignin Pyrolysis. Fuel 2007, 86, 1781-1788.

(53) Tsamba, A. J. Fundamental Study of Two Selected Tropical Biomasses for Energy: Coconut and Cashew Nut Shells; KTH, 2008.

(54) Abdullah, S. S.; Yusup, S.; Ahmad, M. M.; Ramli, A.; Ismail, L. Thermogravimetry Study on Pyrolysis of Various Lignocellulosic Biomass for Potential Hydrogen Production. Int. J. Chem. Biol. Eng. 2010, 3, 137-141.

(55) Sharp, J. H.; Wentworth, S. A. Kinetic Analysis of Thermogravimetric Data. Anal. Chem. 1969, 41, 2060-2062.

(56) Goenka, R.; Parthasarathy, P.; Gupta, N. K.; Biyahut, N. K.; Narayanan, S. Kinetic Analysis of Biomass and Comparison of Its Chemical Compositions by Thermogravimetry, Wet and Experimental Furnace Methods. Waste Biomass Valorization 2015, 6, 989-1002.

(57) Balasundram, V.; Ibrahim, N.; Kasmani, R. M.; Hamid, M. K. A.; Isha, R.; Hasbullah, H.; Ali, R. R. Thermogravimetric Catalytic Pyrolysis and Kinetic Studies of Coconut Copra and Rice Husk for Possible Maximum Production of Pyrolysis Oil. J. Clean. Prod. 2017, $167,218-228$.

(58) Reina, J.; Velo, E.; Puigjaner, L. Kinetic Study of the Pyrolysis of Waste Wood. Ind. Eng. Chem. Res. 1998, 37, 4290-4295.

(59) Wang, C.; Dou, B.; Song, Y.; Chen, H.; Yang, M.; Xu, Y. Kinetic Study on Non-Isothermal Pyrolysis of Sucrose Biomass. Energy Fuels 2014, 28, 3793-3801.

(60) Quan, C.; Gao, N.; Song, Q. Pyrolysis of Biomass Components in a TGA and a Fixed-Bed Reactor: Thermochemical Behaviors, Kinetics, and Product Characterization. J. Anal. Appl. Pyrolysis 2016, $121,84-92$.

(61) Dingcheng, L.; Qiang, X.; Guangsheng, L.; Junya, C.; Jun, Z. Influence of Heating Rate on Reactivity and Surface Chemistry of Chars Derived from Pyrolysis of Two Chinese Low Rank Coals. Int. J. Min. Sci. Technol. 2018, 28, 613-619.

(62) Chen, D. T. Y. A Testing of Some Dynamic Kinetic Equations. J. Therm. Anal. 1974, 6, 109-117.

(63) Chen, D. T. Y. Effect of Heating Rate on Activation Energies Derived by A Dynamic Kinetic Method. J. Therm. Anal. 1975, 7, 6164.

(64) Jackson, M. A.; Compton, D. L.; Boateng, A. A. Screening Heterogeneous Catalysts for the Pyrolysis of Lignin. J. Anal. Appl. Pyrolysis 2009, 85, 226-230.

(65) Melligan, F.; Hayes, M. H. B.; Kwapinski, W.; Leahy, J. J. Hydro-Pyrolysis of Biomass and Online Catalytic Vapor Upgrading with Ni-ZSM-5 and Ni-MCM-41. Energy Fuels 2012, 26, 6080-6090.

(66) Yang, Y.; Gilbert, A.; Xu, C. Hydrodeoxygenation of bio-crude in supercritical hexane with sulfided CoMo and CoMoP catalysts supported on MgO: A model compound study using phenol. Appl. Catal., A 2009, 360, 242-249. 